\title{
ANÁLISE MULTITEMPORAL DA EXPANSÃO AGRÍCOLA NO MUNICÍPIO DE JUAZEIRO (BAHIA) NO PERÍODO DE 1985 A 2006 E SUAS REPERCUSSÕES NO USO DA TERRA
}

\author{
Selma Barbosa Bastos ${ }^{1}$; Rosângela Leal Santos ${ }^{2}$ \\ 1. Bolsista PIBIC/FAPESB, Graduada em Licenciatura em Geografia, Universidade Estadual de Feira de Santana, e-mail: \\ selambbastos@gmail.com \\ 2. Orientador, Departamento de Tecnologia, Universidade Estadual de Feira de Santana, e-mail: \\ rosangela.leal.uefs@gmail.com
}

PALAVRAS-CHAVE: agricultura irrigada; sensoriamento remoto; uso da terra.

\section{INTRODUÇÃO}

Com a implementação de diversas políticas agrícolas pelo Estado a partir da década de 60 do século XX, modernas tecnologias foram incorporadas ao espaço rural (SILVA, 1993), garantindo uma nova dinâmica da produção agrícola e da questão agrária no país.

Nesse contexto, o Governo Federal concentrou investimentos para a criação de infraestrutura de irrigação e geração de energia elétrica na região do Vale do Rio São Francisco (CONDEVASF, 2016), abrindo possibilidades para esta região tornar-se um ambiente propício à implantação de diversos projetos de irrigação (SOUZA, 2013). O município de Juazeiro-BA foi um dos que recebeu investimentos para a implantação da agricultura irrigada, o que gerou diversas repercussões no uso da terra.

A mudança no uso da terra possui caráter dinâmico numa relação tempo-espaço, necessitando de uma análise multitemporal para o entendimento das transformações ocorridas ao longo dos anos. Assim, considera-se imprescindível o uso de técnicas de geoprocessamento e sensoriamento remoto aliadas o Sistema de Informações Geográficas (SIGs) para o auxilio das análises espaciais, uma vez que segundo Jansen (2000) estas técnicas são indispensáveis para o mapeamento do uso da terra em um curto espaço de tempo.

Diante disso, este trabalho teve como objetivo analisar a dinâmica espaço-temporal da agricultura no município de Juazeiro-BA, no período de 1985 a 2006, com vistas à avaliação da mudança do uso da terra após a implantação dos projetos irrigados.

\section{MATERIAL E MÉTODOS}

Juazeiro (Figura 1) foi escolhido como escala espacial de análise, pois, sofreu fortes transformações socioespaciais após a implantação da agricultura irrigada. O município está situado em região é conhecida como a zona de maior aridez do Nordeste do Brasil, caracterizado por longo período de estiagem, que pode se estender até oito meses no ano.

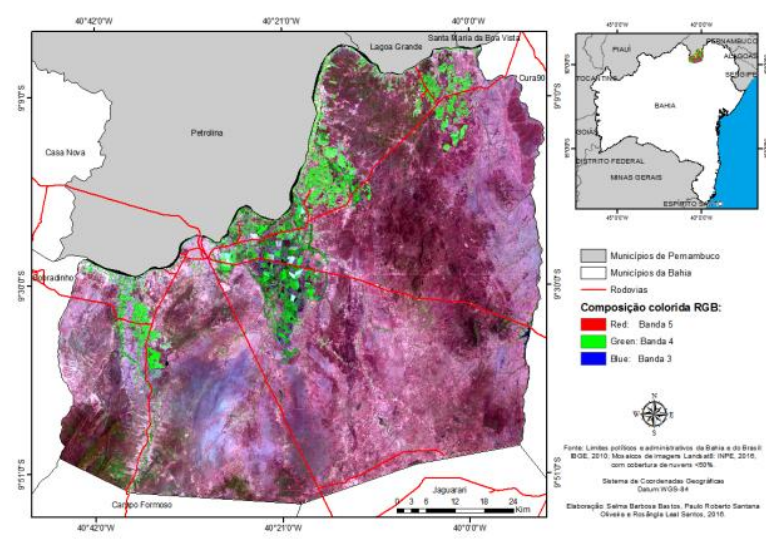

Figura 1. Mapa de localização do município de Juazeiro-BA. 
Foram utilizadas cinco imagens da série Landsat 3 e 5 (órbita/ponto 217_066_067) dos anos de 1985, 1990, 1995, 2000 e 2006. Todas as imagens tiveram que ser mosaicadas, pois o município abrange duas órbitas-ponto. Selecionou-se imagens com menores interferências atmosféricas disponíveis. As imagens foram recortadas a fim de reduzir a área de amostragem para extração das regiões de interesse e consequente classificação. Considerou-se a última imagem como a de maior área ocupada, referente ao ano de 2006 (30/07/2006) e o de 1985 (06/09/1985) o ano de partida, equivalente a imagem mais antiga, onde os projetos ainda eram pioneiros.

Inicialmente escolheu-se dois classificadores: o da Maxima Verissimelhança (Maxver) e o Mahalanobis do ENVI 4.7, utilizando a combinação R5G4B3. No intuito de comparar as classificações e escolher a que melhor representasse o uso da terra espacialmente na série escolhida, foi feita a classificação pelo método de segmentação de imagens, utilizando o classificador Bhatacharya no Spring 4.3.3. Adotou-se esse ultimo classificador, por apresentar melhores resultados. As classes identificadas foram: água, área urbana, área irrigada, caatinga 1 (vegetação densa), caatinga 2 (mata ciliar), caatinga 3 (vegetação espaçada), solo exposto, e em alguns casos de imagens com efeitos atmosféricas, utilizou-se as classes nuvem e sombra.

Os dados da produção agrícola dos anos estudados foram extraídos da Produção Agrícola Municipal fornecida pelo Sistema IBGE de Recuperação Automática (SIDRA) e do Censo Agropecuário de 1985, onde foram consideradas 22 culturas.

\section{RESULTADOS E DISCUSSÃO}

Juazeiro é caracterizado pela agricultura intensiva, que faz usos de métodos modernos de produção e extensas áreas agrícolas irrigadas. Após a implantação dos perímetros irrigados, a produção agrícola municipal ganhou uma nova dinâmica de produção e produtividade. A Tabela 1 mostra que o aumento da quantidade produzida em t da cana-deaçúcar, cebola, melancia e melão refletem a expansão da agricultura irrigada no município, representando $94,3 \%$ de toda a produção do período. Já as culturas de sequeiro como o milho, feijão, e mandioca apresentaram quedas na produção.

A produção de uva, manga e limão tiveram saltos significativos, assim como o mamão, o maracujá e a goiaba. Enquanto a uva, manga e limão representam $64,8 \%$ da produção 209.079 t, o mamão, maracujá e goiaba representam 32,1\% (103.587 t) da produção no período. As culturas da banana e o coco-da-baía apresentaram-se em ascensão (Tabela 2).

Tabela 1. Quantidade produzida em $t$ da lavoura temporária no município de JuazeiroBA, dos anos de 1985, 1990, 1995, 2000 e 2006.

\begin{tabular}{cccccccccccccc}
\hline Cultura & $\begin{array}{c}\text { Algodão } \\
\text { herbáceo }\end{array}$ & Arroz & $\begin{array}{c}\text { Batata- } \\
\text { doce }\end{array}$ & $\begin{array}{c}\text { Cana-de- } \\
\text { açúcar }\end{array}$ & Cebola & Feijão & Mamona & Mandioca & Melancia & Melão & Milho & Tomate \\
\hline 1985 & 707 & 300 & 132 & 440.637 & 7.096 & 1668 & 267 & 1.797 & 3.477 & - & 676 & 55.526 \\
1990 & 2056 & 80 & 1.300 & 503.424 & 19.845 & 2.812 & 90 & 5.620 & 1.692 & 2.054 & 1.130 & 106.272 \\
1995 & 9 & 220 & 1.480 & 1.011 .711 & 10.080 & 4.206 & 23 & 10.070 & 5.109 & 9.108 & 4.894 & 79.236 \\
2000 & 167 & 80 & - & 1.242 .743 & 20.097 & 1.798 & 249 & 63.592 & 2.812 & 8.160 & 1.059 & 13.905 \\
2006 & - & - & - & 1.605 .120 & 40.732 & 659 & - & 15.432 & 26.813 & 25.602 & 100 & 20.944 \\
\hline
\end{tabular}

Fonte: IBGE, 2017.

Tabela 2. Quantidade produzida em t da lavoura permanente no município de Juazeiro-BA, dos anos de 1985, 1990, 1995, 2000 e 2006.

\begin{tabular}{ccccccccccc}
\hline Cultura & \multirow{2}{*}{$\begin{array}{c}\text { Algodão } \\
\text { arbóreo }\end{array}$} & Banana & $\begin{array}{c}\text { Coco- } \\
\text { da- } \\
\text { baía }\end{array}$ & Goiaba & Laranja & Limão & Mamão & Manga & Maracujá & Uva \\
\cline { 1 - 7 } & - & 136 & 398 & 258 & - & 78 & 18.844 & 58 & 2.088 & 1.617 \\
$\mathbf{1 9 8 5}$ & 16 & 286 & 180 & - & 1.260 & 5.590 & - & 4.484 & 6.084 & 9.510
\end{tabular}




\begin{tabular}{ccccccccccc}
$\mathbf{1 9 9 5}$ & 9 & 385 & 230 & 3.140 & 1.560 & 6.240 & 1.260 & 4.920 & 6.396 & 12.540 \\
$\mathbf{2 0 0 0}$ & - & 495 & 290 & 10.665 & 1.800 & 18.995 & 8.075 & 14.325 & 8.190 & 35.220 \\
$\mathbf{2 0 0 6}$ & - & 1.236 & 1.496 & 12.877 & - & 21.450 & 8.550 & 36.942 & 17.160 & 37.110 \\
\hline
\end{tabular}

Fonte: IBGE, 2017.

Com os investimentos federais e internacionais, a agricultura irrigada promoveu um grande dinamismo na economia e na estrutura urbana de Juazeiro, tornando-se um dos aglomerados urbanos mais prósperos do Vale do São Francisco (CORREIA, et al., 2001).

Além do aumento da produção da fruticultura, observa-se uma mudança brusca nas formas de uso da terra, tais como: aumento da área irrigada, expansão da área urbana, supressão da cobertura vegetal (Tabela 3), além da construção de barragem e canais para o armazenamento e transporte de água para a irrigação dos cultivos.

Tabela 3. Uso da Terra no município de Juazeiro-BA em hectares e \%, dos anos de $1985,1990,1995,2000$ e 2006.

\begin{tabular}{c|ccccccccccc}
\hline Classe & \multicolumn{3}{|c}{$\mathbf{1 9 8 5}$} & \multicolumn{9}{c}{$\mathbf{1 9 9 0}$} & \multicolumn{3}{c}{1995} & \multicolumn{3}{c}{2000} \\
\hline Água & $0,9 \%$ & 5698,01 & $1,02 \%$ & 6640,05 & $0,3 \%$ & 1957,21 & $0,3 \%$ & 2102,26 & $0,2 \%$ & 1134,05 \\
$\begin{array}{c}\text { Área } \\
\text { Urbana } \\
\text { Área } \\
\text { Irrigada }\end{array}$ & $0,3 \%$ & 1950,73 & $0,3 \%$ & 1821,17 & $0,3 \%$ & 1813,36 & $0,2 \%$ & 1843,40 & $0,2 \%$ & 1453,71 \\
Caatinga 1 & $0.8 \%$ & 5035,43 & $2,4 \%$ & 18414,75 & $1,9 \%$ & 12446,06 & $1,9 \%$ & 12531,60 & $3,9 \%$ & 24619,91 \\
Caatinga 2 & $24.2 \%$ & 154728,30 & $42,1 \%$ & 272726,29 & $38,4 \%$ & 245454,82 & $31,9 \%$ & 203833,63 & $37,7 \%$ & 240190,56 \\
Caatinga 3 & $22,2 \%$ & 159769,59 & $3,5 \%$ & 22981,94 & 5,9 & 38214,28 & $11,1 \%$ & 71101,22 & $5,6 \%$ & 36388,86 \\
$\quad$ Solo & $20,1 \%$ & 127909,95 & $30,6 \%$ & 198491,99 & $33,4 \%$ & 213820,63 & $14,2 \%$ & 91152,52 & $37,5 \%$ & 239481,79 \\
Exposto & 142623,44 & $19,5 \%$ & 126623,34 & $19,5 \%$ & 124848,57 & $26,1 \%$ & 166992,38 & $14,9 \%$ & 95216,37 \\
Nuvem & $1,5 \%$ & 10015,28 & - & - & - & - & $8,2 \%$ & 52666,64 & - \\
Sombra & $4,6 \%$ & 29776,59 & - & - & - & - & $5,5 \%$ & 35394,05 & - \\
\hline
\end{tabular}

Elaborado pelo autor.

Em 1985 a área irrigada ainda era incipiente em Juazeiro, ocupando 0,8\% da área do município. No ano de 1990, observa-se um aumento 1,6\% em relação a 1985 da área irrigada. A classe caatinga 1 apresentou um crescimento de 17,9\%, por outro lado, a caatinga 2 reduziu $21.7 \%$, o que pode ter relação direta com o aumento da caatinga 1 . O solo exposto, por sua vez, apresentou um percentual de 30,6\%, 10,5\% a mais que em 1985.

Em 1995 houve redução da área irrigada $(1,9 \%)$ e da caatinga $1(38,4 \%)$, por outro lado, aumento da classe de solo exposto $(33,4 \%)$. Infere-se que isso decorre do fato da cena selecionada corresponder a um período de ausência de chuva. Em 2000 destaca-se o aumento das áreas de caatinga $2(11,1 \%)$ e caatinga $3(26,1 \%)$, e redução do solo exposto $(14,2 \%)$. Por ser uma imagem de uma época chuvosa, as classes de vegetação apresentaram quase $1 / 3$ de toda a área mapeada, enquanto as áreas com solo exposto regrediram, passando de $33,4 \%$ para $14.2 \%$. Neste ano, a área irrigada apresentou 1,9\% (12.531,60 ha) da área mapeada, o mesmo percentual de 1995.

O ultimo ano da série, 2006, áreas classificadas como área irrigada e solo exposto aumentaram $2 \%$ e $23,3 \%$, respectivamente. Isso pode estar uma cena do período marcado pela estiagem. Observa-se aumento da caatinga $1(37,7 \%)$ e redução nas demais, caatinga $2(5,6 \%)$ e caatinga $3(14,9 \%)$.

A agricultura irrigada em Juazeiro teve um aumento significativo em sua área plantada entre 1985 a 2006, substituindo áreas que outrora eram de domínio das culturas temporárias (CORREIRA, et al. 2001). Essa nova dinâmica agrícola modificou as relações sociais e de produção, (re) produziu o espaço rural e gerou diversas repercussões para a agricultura familiar, pois a modernização da agricultura foi seletiva e excludente. 

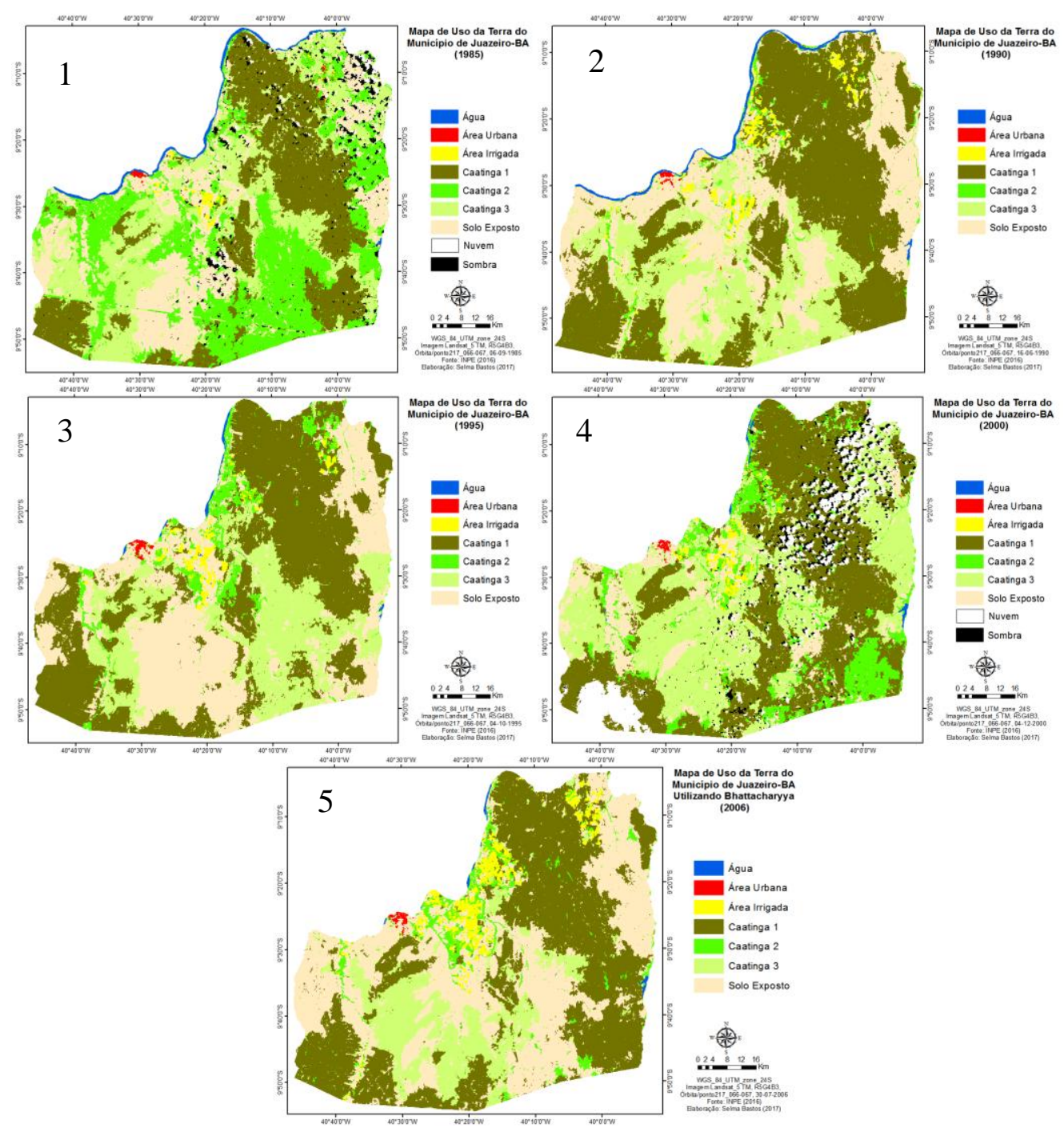

Figuras 2, 3, 4 e 5. Mapa de uso da terra do município de Juazeiro-BA de 1985, 1990, 1995, 2000 e 2006.

\section{CONSIDERAÇÕES FINAIS}

Houve um aumento significativo do perímetro irrigado do município de Juazeiro-BA ao longo das décadas estudadas. Destaca-se a utilidade do sensoriamento remoto para a quantificação e espacialização do uso da terra, a partir do processamento digital de imagens bem como da classificação Battacharyya. Ressalta-se a necessidade de trabalho de campo para a validação dos resultados, o que garantirá maior confiabilidade a pesquisa.

\section{REFERÊNCIAS}

Companhia de Desenvolvimento dos Vales do São Francisco e Parnaíba (CONDEVASF). Disponível em: < http://www.codevasf.gov.br/>. Acesso em: 23.out.2016.

CORREIA; R. C.; ARAÚJO, J. L. P.; CAVALCANTI, E. B. A fruticultura como vetor de desenvolvimento: o caso dos municípios de Petrolina (PE) e Juazeiro (BA). [S.1.]: [s.n.], 2001. Jensen, J.R. Sensoriamento remoto do ambiente: uma perspectiva em recursos terrestres. São José dos Campos: Parêntese, 2009. 604 p.

SILVA, J. G. da. O que é questão agrária. $2^{\circ}$ ed. São Paulo: Brasiliense, 1993.

SOUZA, D. T. M. de. Salinização em Peri metros irrigados: o caso do perímetro irrigado Mandacaru- Juazeiro (BA). 2013. 133 p. Departamento de Pós-Graduação em Geografia da Universidade Federal da Bahia, Salvador, 2013. Dissertação. 